\title{
P138: Soap and handrub consumption survey in Fann Teaching Hospital in Dakar
}

\author{
NM Dia ${ }^{1 *}$, D Faye ${ }^{2}$, BA Niang ${ }^{1}$, M Seydi $^{1}$ \\ From 2nd International Conference on Prevention and Infection Control (ICPIC 2013) \\ Geneva, Switzerland. 25-28 June 2013
}

\section{Introduction}

The prevention of Health care-associated infections (HAI) remains a stake in Public health. The hand is the main mode of transmission of microorganisms. So, hand hygiene is considered to be the primary measure necessary for reducing HAI.

\section{Objectives}

The objective of our work is to measure the consumption of Alcohol-bases-handrub (ABHR) and soap intended for hand hygiene.

\section{Methods}

A prospective investigation before the intervention was realized over a period of six months, of October 1st, 2011 to March 31 2012, with nine clinical departments of a hospital with 347 beds, where a manufacturing unit of ABHR in its WHO formulation was set up under the aegis of the APPS WHO program. The index form finalized by WHO was used.

\section{Results}

In this public tertiary care hospital which employs 360 permanent nursing staff, the monthly average attendance is 2620 patients and number of admissions of 800 a month. During the study period, $77 \%$ of the investigated departments used the ABHR among which $57 \%$ in the form of solutions, $28 \%$ in the form of gels and $15 \%$ in the form of gels and solutions. The supply in ABHR was made in $58 \%$ in the manufacturing unit of the central pharmacy. The monthly average ABHR consumption of the structure was 14.78 liters for a expected quantity of 1635 liters; that of liquids soaps 192 liters; that of soap bars18.6 liters. The average composite indicator of consumption of ABHR was $7.82 \%$ with a minimum monthly use in the Emergency department and a maximum of $30.22 \%$ in the oral department. The FANN teaching hospital was consequently classified $\mathrm{E}$ according to the achievement of the personalized objective, that is an establishment under $10 \%$ of ICSHA.

\section{Conclusion}

In spite of the existence of a manufacturing unit of ABHR, this consumption is still very low. The implementation of the WHO multimodal hand hygiene improvement in particular raising awareness and training, will help in a better compliance and use.

\section{Disclosure of interest}

None declared.

\section{Author details}

'Infectious Diseases Department, Fann Teaching Hospital, Fann, Senegal. ${ }^{2}$ Central Pharmacy, Fann Teaching Hospital, Fann, Senegal.

Published: 20 June 2013

doi:10.1186/2047-2994-2-S1-P138

Cite this article as: Dia et al.: P138: Soap and handrub consumption survey in Fann Teaching Hospital in Dakar. Antimicrobial Resistance and Infection Control 2013 2(Suppl 1):P138. 